\title{
Indicators of the resource efficiency development in Russia
}

\author{
Svetlana $\mathrm{Korol}^{1}$, Natalia Shushunova ${ }^{2}$, and Tatiana Shushunova ${ }^{3, *}$ \\ ${ }^{1}$ Kuban State Technological University, Moscowskaya street, 2, Krasnodar, 350072, Russia \\ ${ }^{2}$ Moscow State University of Civil Engineering, Yaroslavskoe shosse, 26, Moscow, 129337, Russia \\ ${ }^{3}$ Mendeleyev University of Chemical Technology of Russia, Institute of Economics and Management, \\ Miusskaya sq., 9, 125047, Moscow, Russia
}

\begin{abstract}
Inclusion of the carbon component in the standard STO NOSTROY "Green construction" is the part of the study of institutional aspects of the introduction of energy efficiency standards. In the course of this study, based on the generalization of international experience, proposals are being developed to develop mandatory and voluntary carbon reporting in accordance with the concept of sustainable development in Russia, and a rationale is being developed for incorporating the requirements for reducing greenhouse gas emissions within a voluntary certification of real estate "Green Standards" and other systems.
\end{abstract}

\section{Introduction}

Economic crises of recent years, accompanied by a decline in production, contributed to the development of new economic models that reduce the contradiction between the economy and the environment, and provide for long-term sustainable development. One of them was a "green" economy, in which ecology is not a deterrent as in the traditional model, but an engine of development. The concept of the "green" economy is based on earlier economic theories, including welfare and quality of life theories, neo-Malthusian theory, the theory of limits of economic growth, the theory of innovative development, institutional economics and the behavioral economy. In Russia, unlike many countries that have rich natural resources, the need for "green" transformations is the task of systemic changes in several directions: technological, energetic, social, and in the future they will influence the ratio of counterbalancing elements (parties) of power with the goals of society, will become an important condition for equilibrium in the state-society system and determine development, adaptation to the requirements of changes in the external environment [1].

From the standpoint of the technology approach, the sustainable development model and the green economy involve the transition of production to advanced clean technologies, the use of the best available technical methods for the use of energy resources, the development of a system of indicators, criteria and indicators of sustainable development. For the formation of the national concept of sustainable development of Russia, it is important to study and use the vast foreign experience, the rating systems of world leaders. At the same

\footnotetext{
"Corresponding author: nshushun@gmail.com
} 
time, the Russian "green building" needs a national scale that can take into account regional peculiarities, state priorities, peculiarities of the current situation in the construction sector, the Russian mentality.

\section{Rating systems aimed at reducing the consumption of energy resources}

In the construction industry, the driver of economic growth in Russia, the National Association of Builders of the Russian Federation (NOSTROY), in the interests of the participants in the construction process and consumers of building materials and construction products (buildings and structures), a voluntary conformity assessment system (DOS NOSTROY) part of the life cycle of construction and extends to the industry of building materials and other products used in construction. Standard NOSTROY 2.35.4-2011 "Green building. The building is residential and public. The rating system for assessing habitat stability "introduces the concept of" habitat stability "and establishes a rating system for assessing the sustainability of people's habitats in meeting their needs in a comfortable living environment and performing public functions through the use of residential and public buildings without reducing the level of such opportunities for subsequent generations [2].

The knowledge-intensive developments in the field of energy-efficient construction research is reflected in the studies $[11,12]$. The requirements of national standards, construction and sanitary norms, rules and methodological documents, as well as the main provisions of the foreign rating systems LEED (USA), BREEAM (Great Britain), DGNB and HQE (France).

The stability of the habitat in the System is assessed by the combination of the following basic criteria:

- energy saving and energy efficiency;

- consumption of heat energy for heating and ventilation of the building;

- heat consumption for hot water supply;

- electricity consumption;

- the specific total consumption of primary energy for engineering support systems;

- application of alternative and renewable energy;

- use of secondary energy resources;

- use of renewable energy resources;

- environmental protection in the creation, operation and disposal of the facility;

- minimization of the environmental impact of building materials.

Another confirmation of the correctness of the thesis about the need to form a national rating system was the standard NOSTROY 2.35.68-2012 "Residential and public buildings. Accounting for regional peculiarities in the rating system of assessing the sustainability of the habitat ", aimed at the development and expansion of the field of the standard STO NOSTROY 2.35.4-2011 [3]. The standard allowed to take into account the regional differences in Russia and introduced the procedure for taking into account the features of the regions of the Russian Federation that differ in terms of climate, resource potential, the potential of alternative energy and economic potential. The table includes tables with correction factors. Thus, the thesis about the attention of developers to the use of alternative sources of energy and, thereby, to limit the impact on the climate, has manifested itself in a new standard.

\section{Improvement of the NOSTROY rating system}


Despite the presence of positions related to energy efficiency and the use of renewable energy sources, at the present time in the rating system of STO NOSTROY assessment there is no direct account of emissions of greenhouse gases. Accounting for greenhouse gas emissions is particularly relevant in the light of Presidential Decree No. 752 of September 30, 2013 "On Reducing GHG Emissions", which aims to ensure that by 2020 the amount of greenhouse gas emissions at a level not exceeding $75 \%$ of the volume of emissions in 1990, Therefore, the assessment of emissions and their accounting can be organized by recalculating existing indicators using approaches that are prevalent in Europe and, in particular, in the UK.

In our opinion, it may be recommended, for example, to charge an additional number of points in the EDS NOSTROY system for the development and dissemination of open carbon reporting or open reporting containing a section on greenhouse gas emissions, as well as for using low-carbon or carbon -neutral technologies:

As a starting point for the improvement of the SDS NOSTROY rating system, the criteria used in the BREEAM methodology [8] can be used. According to the technical guidelines, new credits are credited to the following categories:

- Energy 01: reduction of CO2 emissions - 15 credits available;

- Energy 02: energy monitoring - 1 credit is available;

- Energy 04: Low-carbon or carbon-neutral technologies - 5 credits are available.

For the calculation of scores (credits), the BREEAM methodology uses convenient formalized approaches, and also takes into account the emissions produced by transport, therefore the significance of the indicators characterizing the accessibility of public transport should be taken into account not only from the logistic, but also from the ecological point of view. This is likely, since SES NOSTROY is inclined to expand, to include additional objects and indicators. For example, during the formation of the Voluntary Assessment of Compliance System in 2011, it was decided that, in addition to taking into account the energy efficiency indicators directly in the standard NOSTROY 2.35.4-2011 and in the rating system of evaluation, it is advisable to provide a separate block of the system, dedicated to promoting the idea of increasing energy efficiency in construction and in the production of building materials [4]. These areas allow the inclusion of the carbon component in the EDS NOSTROY and offer a wide range of opportunities to account for greenhouse gas emissions as priority environmental aspects in the area of responsible supply of construction materials and as criteria for assessing buildings.

\section{Results}

The analysis of the international experience in the implementation of energy efficiency criteria in construction showed an increase in their importance. The EU Directive on the energy characteristics of buildings, which is taken into account in its development by Russian specialists, establishes requirements for new and reconstructed buildings in terms of improving their energy performance. These measures are considered as tools for ensuring energy security and reducing greenhouse gas emissions. In addition, the Directive discusses measures aimed at increasing the number (percentage) of buildings that not only fulfill the minimum requirements for energy performance, but also demonstrate the results of efforts undertaken in the field of increasing energy efficiency, reducing specific energy consumption and reduce $\mathrm{CO} 2$ emissions. Member States are developing national plans to increase the number of carbon neutral buildings and report on the achieved indicators to the European Commission.

The experience of the UK, one of the leaders in the development and implementation of a national strategy for increasing energy efficiency and reducing greenhouse gas emissions from buildings, shows that a range of management solutions aimed at reducing fuel consumption is needed to implement the policy of energy efficiency of construction; flexible 
tariff system; solutions for reconstruction, including, replacement of windows, doors, insulation of walls, roofs, underground facilities; use of renewable energy sources; the use of modern (smart) measuring instruments.

At present, certification bodies are functioning within the framework of EDS NOSTROY, and work is underway to confirm the compliance of integrated management systems, environmental management systems and management systems in the field of occupational safety and labor protection. Russian organizations that are not included in the supply chains of Western companies do not consider greenhouse gas emissions among environmental aspects of governance. The situation may change if measures are adopted in Russia to promote carbon reporting. Thus, the carbon component, theoretically embedded in environmental management systems, can be practically developed in SES NOSTROY.

Another direction of inclusion of the carbon component in SDOS NOSTROY could be requirements for management systems of suppliers of products for construction. Decisions of a particular organization on procurement affect society and the environment far beyond the immediate impact of its own activities. A responsible approach throughout the supply chain can stimulate demand for products that are preferable from the social and environmental point of view. Within the framework of the British, American and Russian systems, only BREEAM includes requirements for the systems of management of suppliers of products for construction [5,6]. In SOS NOSTROY these requirements are formally present, since certification bodies work with enterprises that produce products used in construction. It is necessary to clarify the positions of SESN NOSTROY and the use of a scoring system that would allow not only the advancement of modern management systems, but also the account of the life cycle of construction as a whole. In order to unify the requirements for suppliers in the UK, the Framework for Responsible Supply of Building Materials BES 6001 has been developed that describes aspects of organization management, supply chain management, and environmental and social aspects that should be taken into account when selecting and certifying response suppliers of building materials [7].

\section{Conclusions}

Thus, the rating system is aimed at reducing the consumption of energy resources, the use of non-traditional, renewable and secondary energy resources, rational water use, reducing harmful environmental impacts in the process of construction and operation of the building, including the adjacent territory, comfortable human environment and adequate economic profitability of architectural, constructive and engineering solutions. The requirements of the standard BES 6001: 2009 stipulate the availability of implemented and certified quality management systems for enterprises of the building materials industry; systems of ecological management; Management systems in the field of occupational safety and labor protection. This document stimulates companies seeking to occupy a worthy place in the building materials market, to improve their management systems. The obligatory requirement of the BES 6001 standard is the need to trace $60 \%$ of the materials in the supply chain in those organizations that sell or purchase raw materials, the production of materials as a result of recycling, the production of by-products or residues, the processing of chemicals, sold as raw materials. For higher ratings, the indicators are set at $75 \%$ and $90 \%$.

According to the requirements of the BES 6001 standard, in the context of reducing the impact on the climate system for construction companies, it is mandatory to adopt policies and indicators for reducing greenhouse gas emissions. To obtain a higher rating of results, the organization should formulate goals and objectives in the field of reducing greenhouse gases and carry out an analysis of its effectiveness. 


\section{References}

1. T.N. Shushunova, O.T. Shipkova, G.E. Shaldina, Trans-port business of Russia 1, 45-47 (2017)

2. URL : http://www.nostroy.ru/sitePage.do?name=leftmenu0\&id=13

3. URL : http://www.nostroy.ru/sitePage.do? name=leftmenu0\&id=136

4. URL : http: // cert-nostroy.ru/public/ns_bdocs/6_pdf.pdf

5. Russian Standard GOST R ISO 50001-2012

6. Russian Standard GOST R 54964-2012, http://docs.cntd.ru/document/gost-r-549642012

7. BES 6001: ISSUE 2.0. Framework Standard for the Responsible Sourcing of Construction Products, http://www.greenbooklive.com/filelibrary/responsible_ sourcing/BES_6001_Issue2_Final.pdf

8. BREEAM Communities International Technical Standard, http: // www.breeam.com/discover/technical-standards/communities/

9. Russian Standard GOST R 51541-99

10. Russian Standard GOST R 51387-99

11. O.A. Korol, Construction Materials 6, 13-15 (2015)

12. E. Korol, P. Kagan, T. Barabanova, I. Bunkina, International Journal of Applied Engineering Research 11-3, 1691-1693 (2016) 